\title{
Person-Environment Fit Approach to Intolerance of Inequity
}

\author{
and Free-Riders
}

\author{
Kamarul Zaman Ahmad \\ Faculty of Business \& Accountancy, University of Malaya \\ Kuala Lumpur, Malaysia \\ E-mail: drkamphd@yahoo.com, Website: http://www.drkamphd.com
}

\begin{abstract}
This study uses the person-environment fit approach to assess the dissatisfaction one has towards co-workers who fail to carry their own weight, in groups of varying sizes. It is posited in these studies that in large groups where situations are more likely to be inequitable, highly sensitive people are more intolerant of inequity and thus more dissatisfied with their co-workers, compared with less sensitive ones. Sensitivity was measured as a personality trait by the $16 \mathrm{PF}$ (Cattell et al., 1987) and group size (obtained from company records) was the objective measure of the work environment. On the basis of data from 257 factory workers in Wales, UK, results of hierarchical multiple regression generally indicated that the relationship between sensitivity and co-worker satisfaction are moderated by group size such that the relationship is positive in small groups and negative in large groups.
\end{abstract}

Keywords: P-E fit, Objective fit, Equity theory, Sensitivity, Group size, Co-worker satisfaction, Hierarchical multiple regression

\section{Introduction}

There is an abundance of research that examined the degree of fit between the person and the environment i.e. person-environment fit or P-E fit and how that is associated with satisfaction (Kristof, 1996). However, no studies have attempted to use P-E fit theory to explain why some people are more dissatisfied than others even though they are all placed in the same inequitable situation. Equity theory as proposed by Adams, $(1963,1965)$ also assumes that all people are equally intolerant of inequity. This research examines the personality trait of sensitivity and aims to show how people who are highly sensitive are more intolerant of inequitable situations compared with less sensitive people. The objective of this study is to examine the interaction between equity sensitivity (person) and group size (work environment) and how that is associated with co-worker satisfaction (dependent variable). For instance, does the relationship between equity sensitivity and co-worker satisfaction vary with group sizes? This is the main research question that this study aims to answer.

\section{Literature Review}

\subsection{Person-Environment fit or P-E fit and the argument for using objective measures of the work environment}

P-E fit was summarized by Edwards (1996: 292) as follows: "In essence, P-E fit embodies the premise that attitudes, behaviour and other individual level outcomes result not from the person or environment separately, but rather from the relationship between the two (Lewin, 1951; Murray, 1938; Pervin, 1989)." Kristof $(2005,1996)$, Piasentin and Chapman (2006) and Verquer, Beehr and Wagner (2003) have done a thorough literature review and as such, the bulk of it will not be reproduced here. Rather, what is discussed in this paper are the two main ways of conceptualizing fit - direct and indirect. This eventually leads to the researcher's justification and recommendation that the environment should be measured objectively (in order to get a correspondingly objective measure of fit).

Kristof, Zimmerman and Johnson $(2005,1996)$ indicated that some researchers have used direct measures of fit i.e. by asking people explicitly whether they believe a good fit exists. Posner, Kouzes and Schmidt (1985) used such a method. In their study, managers directly rated how compatible their values were with those of their organizations and how often they had to compromise personal principles to meet organizational expectations. This method is plagued by the consistency bias (i.e., "I think that I fit well, so I must be satisfied with my job") and is therefore not adopted in the current research. Due to this drawback, some researchers have relied on indirect measures to assess fit. According to Kristof (1996), indirect measures are more reliable because the respondent is asked to rate the individual separately from the environment without being asked to assess the degree of fit. This method (hereinafter called "the moderator approach") does not insist on commensurate measures. The person and the environment can be measured separately (as they should be), using entirely different instruments. The nature and ranges of the two scales can be entirely different. This does not require the respondent to assess fit either directly or indirectly. In fact, it makes it virtually impossible for the respondent to even attempt to assess fit. In this respect, the moderator approach is superior in that the consistency bias inherent in the direct 
measurement of fit approach can be totally eliminated. However, it can be argued that the biggest advantage with this method is that objective measures of the environment can be used. Objective measures are measures that do not require any conceptual transformation on the part of the respondent. Hence, it is entirely independent of the person (respondent). Unfortunately, many studies that have used the moderator approach have failed to capitalize on this advantage. For example, in Lee, Ashford and Bobko (1990), control was measured perceptually by the respondent. In Barrick and Mount (1993), autonomy was measured perceptually. Edwards (1991) criticized direct measures primarily because they confound the constructs of the person and environment, thereby preventing the estimation of their independent effects. Yet, amazingly, he did just that (in Edwards, 1996) - environmental supplies and personal values (S-V) fit were measured by asking respondents how much of each task was involved in their job and how much of each task they preferred. This procedure was also employed in another research by Livingstone, Nelson and Barr (1997) who also conducted a study that employed a similar measure of S-V fit in their research.

Although Edwards (1991) pointed out that there is a real need for future research to use objective measures (of either the person or the environment), he has not done so himself and there appears to be none done by others reported even until today. Thus, there is a pressing need for a research to be conducted that uses a truly objective measure i.e. one which is obtained from a source other than the respondent.

\subsection{Group Size}

Group size, a measure that can be obtained from company records, is one aspect of the work environment that can be measured objectively. Social interactions in groups are frequently characterized by conflicts between personal and collective interests (De Cremer and Leonardelli, 2003). Thus, it is not surprising that research has shown that smaller groups establish and maintain higher levels of communication (Lowry, Roberts, Romano, Cheney and Hightower, 2006) whereas larger groups have reported lower satisfaction (Frank and Anderson, 1971; Shaw, 1981; Slater, 1958; Worthy, 1950). As group size increases, almost every group experiences some degradation in group communication process due to social loafing (Chidambaram and Tung, 2005; Liden, Wayne, Jaworski, and Bennett, 2009). Dissatisfaction with large groups is also reflected by greater absenteeism and personnel turnover (Shaw, 1981). However, small groups are not always better than larger groups. Aiken and Wong (2003) discovered that for idea generation, groups may not be effective until they reach a certain size. However, this apparent controversy over which size is better can be summed up by Worthy (1950) who stated that mere size is unquestionably one of the most important factors in determining the satisfaction of employees - and dissatisfaction can have serious consequences for the company.

\subsection{Inequity and the personality trait of sensitivity}

Equity theory (Adams, 1963, 1965) proposed that we are concerned with how much we get (outcomes) in proportion to how much we contribute (inputs). According to equity theory, we then compare this ratio with that of another individual to determine whether the situation is equitable. When things are inequitable and the ratios are unequal, we are less satisfied. Huseman, Hatfield and Miles (1987) posited that some individuals are more sensitive to inequity than others. According to Cattell, Eber and Tatsuoka (1992) people whose traits are high on sensitivity crave affection and attention, are also fussy, insecure, anxious, theatrical, easily affected and have been often associated with mental breakdown. Therefore, the extremely sensitive person craves for equity, and it does not matter whether the inputs are greater than the outputs or the other way round - both are undesirable to them. For instance, Irving and Montes (2009) found that exceeded expectations are not always associated with high levels of satisfaction. Accordingly, people whose traits are very high on sensitivity (Cattell et al., 1992) strongly favor equity and also cannot tolerate inequity in either direction, whereas people whose traits are low on sensitivity are more tolerant of inequity. The satisfaction or dissatisfaction that people have concerning equity or inequity can be directed towards their co-workers.

\subsection{Development of Hypotheses}

Thus, the main objective of this study is to determine whether the relationship between the personality trait of sensitivity and satisfaction is moderated by group size. It has also been explained in the literature review that, highly sensitive people are more dissatisfied with inequity than less sensitive people. Since social loafing is more likely to occur in larger groups, it would be reasonable to propose that large groups tend to be inequitable, whereas small groups tend to be more equitable. This is a proposition of course, which has to be tested. Ensuring workload equity is certainly more difficult as the group gets larger, simply because there are more people to consider. Therefore, it would be reasonable to propose that in large groups, highly sensitive people will be more dissatisfied with their co-workers than less sensitive ones. In small groups the relationship would be opposite because it would be easier that all the group members "carry their own weight" i.e. more equitable. Accordingly, the hypotheses are:

Null Hypothesis HO: The association between sensitivity scores and co-worker satisfaction scores is not moderated by group size.

Alternative Hypothesis H1: The association between sensitivity scores and co-worker satisfaction scores is moderated by group size. 
Alternative Hypothesis H2: The association between sensitivity scores and co-worker satisfaction scores is negative for large groups and positive for small groups.

\section{Research Methodology}

\subsection{Sample}

Data on two hundred and fifty seven shop-floor workers who worked in groups were collected from a light manufacturing assembly plant in Wales, UK. The entire population of the workers on the shop-floor was three hundred. The majority of the sample was females - there were one hundred and eighty females $(70 \%)$ and seventy seven males $(30 \%)$. The average age of the sample was thirty five (see Table 1). Test administration took place over a period of three months in the factory. The collection of data on the employees in the sample took place in sessions at which, from three to fifteen employees were present. Subjects were asked to supply their names to identify their work groups. Every attempt was made to reduce the respondents' worries and anxieties about participating in the research and that this research was mainly for academic purposes. The rationale for choosing to study only one organization was to reduce the variance due to factors which are not measured but must still be controlled (or at least be subjected to some attempt at control). Examples of such factors are differences in company policies, company size, industry sector and geographical location. Adkins Ravlin and Meglino (1996), in their research (which has some similarities with this research), also confined their study to one organization (one-hundred and ninety-one production workers). Thus, it will actually be counter-productive to collect the data from different organizations in this case. Bouchard (1983: 367) stated "Many field studies involve only one organization or subject. While the one case study is generally sterile scientifically.... it need not be. ... A well chosen single case may seriously threaten a traditionally accepted hypothesis."

\subsection{Measures}

Group size was measured by the number of workers in the work team as shown in the company records. Sensitivity was measured by 6 items in the 16 PF (Cattell et al., 1992) that measures Factor I. One such example is "I think what people say in poetry could be put exactly in plain prose." Scoring instructions are provided by Cattell et al., (1992). The 16 PF remains a popular questionnaire until today and still being used by many researchers (Forero, Pujol, Olivares and Pueyo, 2009; Wang and Xu 2008; Cousineau, Hall Mel, Rosik and Hall, 2007). Co-worker satisfaction was measured by numerical scales adapted from another P-E fit study (Meir, Hadas and Noyfeld, 1997), ranged from 1 to 20 (1 being lowest and 20 being the highest level of satisfaction).

\subsection{Operationalising the Moderator}

The moderator term is a compound variable formed by multiplying $u$ by the moderator $v$ that is entered in the regression equation (Hair, Anderson Tatham and Black, 1998). However, an important distinction has to be borne in mind - the $u \times$ $v$ interaction "is carried by," rather than "being" the $u v$ product. The product of $u$ and $v(u v)$ only becomes the interaction term after its constituent elements have been partialled out.

$u \times v=u v \cdot u, v$.

One method of doing this is hierarchical multiple regression - the product " $u v$ " is introduced into the regression equation in step 2 only after the separate independent variables of $u$ and $v$ have been introduced in step 1 . It is thus the partialled $u v$ results that is interpreted as the " $u \times v$ interaction" (Cohen and Cohen, 1983: 305).

According to Cohen and Cohen (1983), the term moderator variable (f) referred to in psychometric literature refers to an IV that potentially enters into interaction with "predictor" $(g)$ variables while having a negligible correlation with the criterion $(Y)$ itself. However, studies in P-E fit are varied in their approach to which variable should be the predictor and which should be the moderator. In Barrick and Mount (1993) the predictor variable was personality (conscientiousness, extraversion and agreeableness) and the moderator variable was the job environment (job autonomy). In Roberts and Foti (1998), however, the predictor variable was the work environment (work structure) and the moderating variable was personality (self-leadership). If P-E fit theory is correct in propagating the view that both personality and environmental variables are important, then it would appear that the approaches in both studies seem acceptable. Furthermore, from a purely statistical viewpoint, the relationship between two interacting variables is symmetric. "If $f$ moderates the regression of $Y$ on $g$, then $g$ moderates the regression of $Y$ on $f$." (Cohen and Cohen, 1983: 323). For the purpose of this study, sensitivity is treated as the predictor and group size as the moderator. However, from a statistical viewpoint, group size could well have been treated as the predictor and sensitivity as a moderator.

\subsection{Hierarchical Multiple Regression Analysis (HMR)}

Hierarchical multiple regression were conducted to test the significance of the moderating effect of group size. In its simplest form, a hierarchical (sometimes called sequential) analysis involves entering the IVs singly or cumulatively in a prespecified sequence. The $\mathrm{R}^{2}$ and partial coefficients are examined at each step. In hierarchical regression "the researcher determines the order in which IVs are entered into the equation," taking into account logical or theoretical considerations (Tabachnick and Fidell, 1996: 149). The IVs ( $u$ and $v)$ can be entered in block 1 of the analyses using the 
command "Enter" in the SPSS program. The interaction term $(u \times v)$ can then be introduced into the equation in block two. The term "introduced" rather than "entered" is used because, in block two, the interaction term is accepted into the equation only if, together with the individual component variables, it explains a variance in the dependent variable significantly more $(\mathrm{p}<.05)$ than the individual component variables alone. If the interaction term can significantly ( $\mathrm{p}$ $<.05)$ improve the predictive power of the equation, then it will form part of the regression equation. If it fails to significantly improve the $\mathrm{R}^{2}$ (squared semi-partial correlation), then the SPSS programme will not include the interaction term from the regression equation. The command used in block 2 was "Stepwise". Results of hierarchical multiple regression analyses are given in section 4.2.

\subsection{Procedure for defining small and large groups}

The purpose of identifying small and large groups was to compare the correlation coefficients between the variables of sensitivity and satisfaction, in small and large groups. The procedure for defining group size is as follows: The entire sample was split into three equal groups according to group size i.e. small, medium and large. Subsequently, only the large groups were compared with the small groups, the two being at the extremes. The basis of dividing the groups as such was to adopt a compromise between two opposing recommendations. Roberts and Foti (1998) and Adkins, Ravlin and Meglino (1996) used median splits to divide their sample into two equal groups and then proceeded to compare one group with another. This method has the advantage of utilizing the entire sample in the analyses. However, the disadvantage with this method is that it will inevitably include those respondents who are at the borderline i.e. just below or just above the mean of the variable under investigation. As such, it was felt that three groups rather than two should be formed and the analyses restricted to the comparison of the two extreme groups only. For instance, Barrick and Mount (1993) divided their entire sample according to $+1,0$ and -1 standard deviation. However, the outcome was that there were rather small sub-samples at both ends of the spectrum $(\mathrm{n}=59$ at the +1 standard deviation above the mean and $n=49$ at the -1 standard deviation below the mean) with a high 'wastage' $(n=149)$ in the middle of the range. The end result was a compromise and the entire sample was divided into three equal groups. The SPSS commands of "summarize - frequencies - statistics - cut points for 3 equal groups" were used to determine the appropriate maximum values for small groups and minimum values for large groups. The result was that groups comprising between two and seven members were classified as small, between eight to fourteen were considered medium, and between fifteen and twenty were considered large.

\section{Results}

\subsection{Reliability}

Cronbach coefficient alpha reliability scores for sensitivity were 0.73 . Cronbach coefficient alpha reliability score for co-worker satisfaction was unavailable since it was a one-item measure. Descriptive statistics are given in Table 1. Correlation coefficients between the main variables are given in Table 2. Sensitivity was not significantly correlated with group size, and co-worker satisfaction. Group size was negatively correlated with co-worker satisfaction $(-.257$, $\mathrm{p}<.01)$.

Insert Table 1 here

Insert Table 2 here

\subsection{Results of Hierarchical Multiple Regression}

Tests of hierarchical multiple regression were used to determine the significance of the interaction term (sensitivity multiplied by the group size) on co-worker satisfaction. The interaction term was successfully accepted into the regression equation after the individual components have been entered into the equation. Full details of the values of $\mathrm{R}^{2}$ are set out in Table 3. For instance Table 3 Column 3 show the values of $R^{2}$ when only the sensitivity variable and the group size were entered into the regression equation (.067). Column 4 of the same table show the $\mathrm{R}^{2}$ when the sensitivity variable and group size as well as the interaction term were all in the equation (.084). Column 5 of the same table show the change in $\mathrm{R}^{2}$ as a result of introducing the interaction term (.017). This $\mathrm{R}^{2}$ multiplied by 100 will give the percentage of the variance that is accounted for by the interaction term after both the individual variables of sensitivity and group size are entered into the equation. Details of the results are given in section 4.2. Thus, results showed support for $\mathbf{H 1}$ in so far as group size was a significant moderator of the sensitivity-satisfaction relationship.

\section{Insert Table 3 here}

\section{Insert Table 4 here}

In order to find out the direction of the relationships as posited by $\mathbf{H 2}$, tests of regression and correlation were conducted between sensitivity and satisfaction, when only large groups were selected and when only small groups were selected for analyses. Results showed support for $\mathbf{H 2}$ in that the relationship between sensitivity and co-worker satisfaction were negative in large groups and positive in small groups, as indicated by the values of $b$ (slope of the regression line) and as evident from Figure 1. Having said that however, only the correlation between sensitivity and co-worker satisfaction was 
significantly positive in small groups $(.273, \mathrm{p}<.01$ : Table 4$)$. Correlation between sensitivity and co-worker satisfaction in large groups was not significant. Table 4 shows the values of $b$ and the correlation coefficients in three scenarios: all cases, large groups only and small groups only. Figure 1 plots out the graphs for large groups, small groups and all cases, for co-worker satisfaction.

Insert Figure 1 here

\section{Conclusion}

The results of this study lends support to the P-E fit theory in that people who fit in their environment tend to be more satisfied than those who do not. Sensitive people fit in working environments where all the group members "carry their own weight". Workload in large groups tends to be inequitable, whereas workload in small groups tends to be more equitable. This is because social loafing is more likely to occur in larger as opposed to smaller groups. Results seem to suggest that, people whose traits are high on sensitivity have a tendency to be less satisfied with their share of the workload if they are made to work in large groups. Highly sensitive people are more satisfied with their share of the workload if they work in small groups where it is easier to ensure that everyone is doing their fair share of the work. The results of this study also support the criticisms of the equity theory in that not all people are equally affected by inequity (Huseman et al., 1985). Results suggest that highly sensitive people are more dissatisfied by inequity (as in large groups) compared with less sensitive ones. Highly sensitive people are also more satisfied in an equitable situation (as in small groups) compared with less sensitive ones.

From the managerial perspective, results seem to suggest that sensitive people should be made to work in smaller groups where they will be more satisfied with their share of the workload, and not in larger groups where they will be less satisfied. However, to be able to do so, management would have to find out which workers are more sensitive and which are less sensitive. This would necessitate personality tests to be conducted on all the workers, a decision which may or may not be popular with the management or the workers. From the person-environment perspective, managers have two choices. Change the person or change the environment. Managers could either select only those people whose traits are low on sensitivity, or they could limit the group sizes so as not to exceed ten in number. The second alternative seems simpler, and this action would probably reduce the occurrence of social loafing hence resulting in increased satisfaction of the average worker. In addition, management can make individual contributions more visible.

\section{Limitations}

Since this study is cross sectional, a conclusion cannot be drawn about the direction of causality in these findings. However, it is reasonable to hold that the interaction between sensitivity and group size was for the most part responsible for changes in satisfaction rather than the reverse as the view taken in this research is that personality traits are relatively stable over long periods of time. Another weakness is that the moderator analyses were conducted in a single company. However, this can be argued to be a strength as many variables such as, company policies, company size, industry sector and geographical location are controlled because the study was conducted in the same factory. Such variables, if uncontrolled, may have varying effects on the moderator, the independent and dependent variables. Furthermore, the findings of this study can easily benefit from replication studies conducted in other companies with the same characteristics.

\section{References}

Adams, J. S. (1963). Toward an understanding of inequity. Journal of Abnormal and Social Psychology, 67, 422-436.

Adams, J. S. (1965). Inequity in social exchange. Advances in Experimental Social Psychology, 2, 267-299.

Adkins, C. L., Ravlin, E. C. \& Meglino, B. (1996). Value congruence between co-workers and it's relationship to work outcomes. Group and Organisation Management, 21(4), 439-460.

Aiken, M. \& Wong, Z. (2003). The effect of group size on electronic idea generation. International Journal of Human Resources Development and Management, 3(3), 265.

Barrick, M. R. \& Mount, M. K. (1993). Autonomy as a moderator of the relationships between the Big Five personality dimensions and job performance. Journal of Applied Psychology, 78(1), 111-118.

Bouchard T. J. JR. (1983). Field research methods: interviewing, questionnaires, participant observation, systematic observation, unobtrusive measures. In Dunnette, M. D. (Ed.), Handbook of Industrial and Organizational Psychology, John Wiley \& Sons.

Cattell, R. B., Eber, H. W. \& Tatsuoka, M. M. (1992). Handbook for the Sixteen Personality Questionnaire. Champaign Illinois: IPAT.

Chidambaram, L. \& Tung, L. L. (2005). Is out of sight, out of mind? An empirical study of social loafing in technology-supported groups. Information Systems Research, 16(2), 149-160. 
Cohen, J. \& Cohen, P. (1983). Applied Multiple Regression/Correlation Analysis for the Behavioral Sciences. (2 ${ }^{\text {nd }}$ ed.) Hillsdale, NJ: Erlbaum.

Cousineau, A. E., Hall Mel, E. L., Rosik, C. H. \& Hall, T. W. (2007). The 16 PF and marital satisfaction inventory as predictors of missionary job success. Journal of Psychology and Theology, 35(4), 317-327.

De Cremer, D. \& Leonardelli, G. J. (2003). Cooperation in social dilemmas and the need to belong: The moderating effect of group size. Group Dynamics: Theory, Research, and Practice, 7(2), 168-174.

Edwards, J. R. (1991). Person-job fit: a conceptual integration, literature review and methodological critique. International Review of Industrial/ Organizational Psychology, 6, 283-357.

Edwards, J. R. (1996). An examination of competing versions of the person-environment fit approach to stress. Academy of Management Journal, 39(2), 292-339.

Forero, C. G., Pujol, D. G., Olivares, A. M. \& Pueyo, A. A. (2009). A longitudinal model for predicting performance of police officers using personality and behavioural data. Criminal Justice and Behavior, 36(6), 591-606.

Frank, F. \& Anderson, L. R. (1971). Effects of task and group size upon group productivity and member satisfaction. Sociometry, 34, 135-149.

Hair, J. F. Jr., Anderson, R. E., Tatham, R. L. \& Black, W. C. (1998). Multivariate Data Analysis. (5 ${ }^{\text {th }}$ ed.). New Jersey: Prentice Hall.

Huseman, R. C., Hatfield, J. D. \& Miles, E. W. (1987). A new perspective on equity theory: the equity sensitivity construct. Academy of Management Journal, 12(2), 222-234.

Irving, P. G. \& Montes, S. D. (2009). Met expectations: The effects of expected and delivered inducements on employee satisfaction. Journal of Occupational and Organizational Psychology, 82(2), 431-451

Kristof, A. (1996). Person-organisation fit: an integrative review of it's conceptualisations, measurement, and implications. Personnel Psychology, 49, 1-49.

Kristof, A., Zimmerman, R. D. \& Johnson, E. C. (2005). Consequences of individuals' fit at work: a meta-analysis of person-job, person-organization, person-group and person-supervisor fit. Personnel Psychology, 58, $281-342$.

Lee, C., Ashford, S. J. \& Bobko, P. (1990). Interactive effects of "Type A" behavior and perceived control on worker performance, job satisfaction and somatic complaints. Academy of Management Journal, 33(4), 870-881.

Lewin, K. (1951). Field Theory in Social Science. New York: Harper.

Liden, R., Wayne, S.J., Jaworski, R.A. \& Bennett, N. (2004). Social loafing: a field investigation. Journal of Management, $30(2), 285$.

Livingstone, L. P., Nelson, D. L. \& Barr, S. H. (1997). Person-environment fit and creativity: an examination of supply-value and demand-ability versions of fit. Journal of Management, 23(2), 119 - 146.

Lowry, P. B., Roberts, T. L., Romano N. C., Cheney, P. D. \& Hightower, R. T. (2006). The impact of group size and social presence on small group communication - does computer-mediated communication make a difference? Small Group Research, 37(6), 631-661.

Meir, E. I., Hadas, C. \& Noyfeld, M. (1997). Person-environment fit in small army units. Journal of Career Assessment, 5 , 21-29.

Murray, H. A. (1938). Explorations in Personality. Boston: Houghton Mifflin.

Pervin, L. A. (1989). Persons, situations, interactions: the history and a discussion of theoretical models. Academy of Management Review, 14(3), 350-360.

Piasentin, K. A. \& Chapman, D. S. (2006). Subjective person-organisation fit: Bridging the gap between conceptualisation and measurement. Journal of Vocational Behaviour, 69, 202-221.

Posner, B. Z., Kouzes, J. M. \& Schmidt, W. H. (1985). Shared values make a difference - an empirical test of corporate culture. Human Resources Management, 24(3), 293-309.

Roberts, H. E. \& Foti, R. J. (1998). Evaluating the interaction between self-leadership and work structure in predicting job satisfaction. Journal of Business and Psychology, 12(3), 257-267.

Shaw, M. E. (1981). Group Dynamics. The Psychology of Small Group Behavior. New York: McGraw Hill.

Slater, P. E. (1958). Contrasting correlates of group size. Sociometry, 21, 129-139.

Tabachnick, B. G. \& Fidell, L. S. (1996). Using Multivariate Statistics. (3 ${ }^{\text {rd }}$ ed.) New York: Harper Collins College Publishers. 
Verquer, M. L., Beehr, T. A. \& Wagner, S. H. (2003). A meta-analysis of relations between person-organization fit and work attitudes. Journal of Vocational Behaviour, 63, 473-489.

Wang, A. P. \& Xu, Y. (2008). Applicability of five-kind of personality inventory for college students' personality measurement: Comparison study with 16PF. International Journal of Psychology, 43(3), 480-480

Worthy, J. C. (1950). Organizational structure and employee morale. American Sociological Review, 15, 169-179.

Table 1. Descriptives

\begin{tabular}{lll}
\hline & Means & Standard deviation \\
\hline Sensitivity & 5.54 & 1.92 \\
\hline Co-worker satisfaction & 13.52 & 3.96 \\
\hline Age & 35.57 & 10.66 \\
\hline
\end{tabular}

$\mathrm{N}=257$

Table 2. Table of correlation coefficients

\begin{tabular}{lccc}
\hline & Sensitivity & Group Size & $\begin{array}{c}\text { Satisfaction with } \\
\text { Co-workers }\end{array}$ \\
\cline { 2 - 5 } Sensitivity & 1 & .775 & .689 \\
\hline Group size & .018 & 1 & .000 \\
\hline Satisfaction with co-worker & .025 & $-.257^{* *}$ & 1 \\
\hline
\end{tabular}

$* * p<.01, \quad \mathrm{~N}=257$

Above diagonal $=$ significance

Below diagonal $=$ Pearson correlation coefficients

Table 3. Tests of Hierarchical Multiple Regression: sensitivity (IV), group size (IV), sensitivity x group size (MV) and co-worker satisfaction (DV)

\begin{tabular}{|c|c|c|c|c|c|c|}
\hline \multirow{2}{*}{$\begin{array}{l}\text { Person } \\
\text { Variable (IV) }\end{array}$} & \multirow{2}{*}{$\begin{array}{l}\text { Environment } \\
\text { Variable (IV) }\end{array}$} & \multirow{2}{*}{$\begin{array}{l}\text { Interaction Term or } \\
\text { Moderating Variable }\end{array}$} & \multirow[t]{2}{*}{ Dependent Variable } & \multicolumn{3}{|c|}{ Hierarchical Multiple Regression } \\
\hline & & & & $\begin{array}{l}\mathrm{R}^{2} \text { with sensitivity and } \\
\text { co-worker satisfaction but } \\
\text { excluding interaction term }\end{array}$ & $\begin{array}{l}\mathrm{R}^{2} \text { including } \\
\text { interaction term }\end{array}$ & $\begin{array}{l}\Delta \\
\mathrm{R}^{2}\end{array}$ \\
\hline Sensitivity & $\begin{array}{l}\text { A. } \\
\text { size }\end{array}$ & $\begin{array}{l}\text { B. Sensitivity } \\
\text { multiplied by group size }\end{array}$ & $\begin{array}{l}\text { C. Co-worker } \\
\text { Satisfaction }\end{array}$ & .067 & .084 & .017 \\
\hline
\end{tabular}

Table 4. Values of $\mathrm{b}$ and the bivariate correlation coefficients between sensitivity and co-worker satisfaction for all cases, large and small groups

\begin{tabular}{lllll}
\hline Variables & Statistical & All Cases & Large Groups & Small Groups \\
& Analysis & $(\mathrm{N}=257)$ & $(\mathrm{N}=90)$ & $97)$ \\
& & .149 & -.233 & .589 \\
\hline $\begin{array}{l}\text { Sensitivity \& co-worker } \\
\text { satisfaction }\end{array}$ & Values of b & -.126 & $.273^{* *}$
\end{tabular}

$* * p<.01, \overline{\mathrm{N}=257}$ 


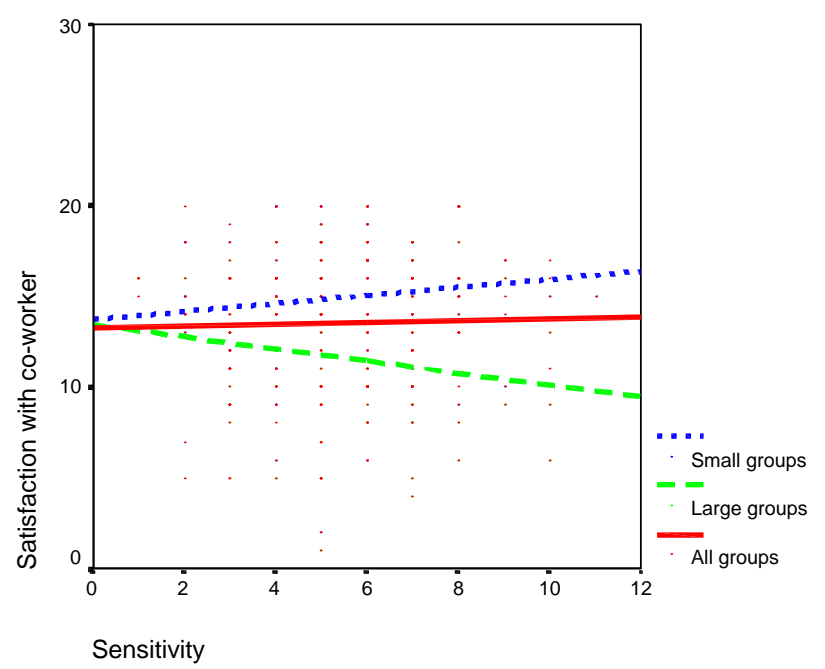

Figure 1. Interactional Effects of Group Size on the Relationship between Sensitivity and Co-worker Satisfaction 